\title{
Developing risk management treatments for taro from the Pacific Islands
}

\author{
Lisa E. Jamieson ${ }^{1, \star}$, Natalie E.M. Page-Weir ${ }^{1}$, Reuben T. Wilkinson ${ }^{1}$, Simon P. \\ Redpath $^{1}$, Amanda J. Hawthorne ${ }^{1}$, Samuel D.J. Brown ${ }^{1}$, Lee T. Aalders ${ }^{2}$, Fa'alelei \\ Tunupopo $^{3}$, Angelika Tugaga ${ }^{4}$, Tanu To'omata ${ }^{3}$, Farhat Shah $^{5}$, Jack W. Armstrong ${ }^{6}$, \\ and Allan B. Woolf ${ }^{1}$ \\ ${ }^{1}$ The New Zealand Institute for Plant \& Food Research Limited, Private Bag 92169 Mt Albert, \\ Auckland, New Zealand \\ ${ }^{2}$ AgResearch Ltd, Ruakura Research Centre, Private Bag 3123, Hamilton, New Zealand \\ ${ }^{3}$ MAF Samoa, Nu'u Research Station, Apia, Samoa \\ ${ }^{4}$ Scientific Research Organisation of Samoa (SROS), Samoa \\ ${ }^{5}$ The New Zealand Institute for Plant \& Food Research Limited, Private Bag 4704, Christchurch, \\ New Zealand \\ ${ }^{6}$ Quarantine Scientific, PO Box 408204, Kerikeri East 0248, New Zealand \\ ${ }^{*}$ Corresponding author: Lisa.Jamieson@plantandfood.co.nz
}

\begin{abstract}
Most taro imported from the Pacific are currently fumigated with toxic methyl bromide to kill pests, predominantly mites and nematodes that are generally found on the surface of taro. Combined high-pressure washing (HPW) and hot water treatment (HWT) were examined as alternative methods for disinfesting taro. Taro mites (Rhizoglyphus sp.) and root knot nematodes (Meloidogyne sp.) were exposed to a range of HWT and HPW conditions separately or together. At $47^{\circ} \mathrm{C}$, mean lethal times of 2.6-2.9 mins and 3.9-4.1 mins were estimated to control $99 \%$ and $99.99 \%$ of nymph and adult mites, respectively. Mite nymphs and adults were more tolerant to HWT than mite eggs. The mean lethal time estimate to control $99 \%$ of juvenile nematodes was 4.5 mins. Nematode eggs were the most tolerant life stage with only $10 \%$ mortality after a $4-\min 47^{\circ} \mathrm{C}$ HWT. HPW $+\mathrm{HWT}$ reduced heavy infestations of mobile pests on taro ( $\mathrm{n}=30-117 /$ taro) by $100 \%$. HPW followed by HWT $50^{\circ} \mathrm{C}$ for 12.5 mins reduced viable egg infestation by $95.8 \%$. HPW followed by HWT can control surface pests on taro while maintaining taro quality.
\end{abstract}

Keywords taro mite, root knot nematode, taro, high pressure washing, hot water treatment, biosecurity, disinfestation.

\section{INTRODUCTION}

The New Zealand Ministry for Primary Industries (MPI) requires that the fresh corms of imported root crops, such as taro (Colocasia esculenta (L.) Schott), be free of exotic pests (MPI 2018). Organisms that are frequently carried on corms include mites, nematodes, ants, snails, and larvae of soil-dwelling beetles (Page-Weir et al. 2013). Existing border-treatment protocols for root crops require fumigation with methyl bromide
(MB) on arrival when pests are detected (MPI 2018), with various durations for different pests. The MB treatments used are $48 \mathrm{~g} / \mathrm{m}^{3}$ at $12^{\circ} \mathrm{C}$ for $24 \mathrm{~h}$ if snails are found, $48 \mathrm{~g} / \mathrm{m}^{3} \mathrm{MB}$ at $10-15^{\circ} \mathrm{C}$ for $4 \mathrm{~h}$ if nematodes are found, and $48 \mathrm{~g} / \mathrm{m}^{3} \mathrm{MB}$ at $10-15^{\circ} \mathrm{C}$ for $2 \mathrm{~h}$ if other pests, e.g. mites, are found. Although not all pests found on the root crops are 'unwanted organisms', importers often choose to have their consignment fumigated and released immediately rather than wait for the 
organisms in question to be identified by MPI.

Of the 13.3 million kilograms of taro (965 shipments) that arrived in New Zealand from Fiji, Tonga, Samoa, Niue and the Cook Islands between July 2015 and June 2016, approximately $81 \%$ by weight (or $76 \%$ by shipment) was fumigated (K. Glassey, MPI data).

Methyl bromide is an ozone-depleting, toxic substance and is being phased out (UNEP 2014). In 2011, controls on the use of MB became more restricted in New Zealand because of safety concerns (NZERMA 2011). Furthermore, New Zealand has passed legislation that will require operators to have systems for the complete capture and/or destruction of $\mathrm{MB}$ after fumigation, which must be in place by 2020 (Gear 2011). Eventually $\mathrm{MB}$ is likely to become both difficult to obtain and too costly to use as a fumigant. Additionally, $\mathrm{MB}$ causes damage to many commodities, such as taro, particularity if they are fumigated for $24 \mathrm{~h}$, as is required for treating snails. Like many other countries, New Zealand is seeking alternative treatment methods that will eliminate or reduce the potential for unwanted organisms to be found on imported produce, while maintaining the quality of the produce.

High pressure washing (HPW) is being used to remove pests and surface contaminants from a range of commodities (Woolf et al. 2015). Inspection of taro at the border, targets soil on the taro surface which is where nematodes are more likely to be found. HPW has the potential to remove surface pests and soil and reduce fumigation rates of taro. Griffin et al. (2014) used HPW in New Caledonia to remove surface pests from lime exports to New Zealand and reduced fumigation rates from $100 \%$ to $1.2 \%$.

Previous research indicated that hot water treatment (HWT) has the potential to disinfest taro corms targeting mites and nematodes (Buli et al. 2015, Jamieson et al. 2016, Page-Weir et al. 2013). Lethal times for adult mould mite, Tyrophagus putrescentiae, and adult taro mite, Rhizoglyphus minutus, ranged between 3-6 minutes at temperatures between 47.5 and $49^{\circ} \mathrm{C}$ (Jamieson et al. 2016, Page-Weir et al. 2013). It takes tme for the surface of taro to reach lethal temperatures (e.g. $47^{\circ} \mathrm{C}$ ), therefore the heating up time would need to be incorporated in to the treatment time. Additionally if pests were found beneath the surface of taro further heating time would be required.

This paper summarises results of trials to determine: (1) what pests are found on taro and where they occur (surface or below surface); (2) what the heating profiles of taro are; (3) the most tolerant life stages of taro mite and root knot nematode to HWT; and (4) the efficacy of HPW, HWT and a combination treatment against pests on taro.

\section{MATERIALS AND METHODS Identification of invertebrates collected off taro corms}

In 2016, 100 taro were purchased from growers in Samoa that contained soft patches (rotting indentations) likely to harbour mites. Soft patch sections of taro were inspected under a microscope (10-20 $\times$ magnification). Specimens of mites were collected into $95 \%$ ethanol and identified by Zhi-Qiang Zhang (Manaaki Whenua, Auckland, New Zealand).

In 2017, low-quality taro infested with pests were purchased from growers in Samoa for HPW and HWT trials. Whole taro were inspected under a $10 \times$ hand lens with LED lights and the number of arthropods estimated. Specimens of invertebrate species of interest that could not be easily identified, were collected into ethanol. These specimens were taken back to New Zealand and identified in the laboratory. Mites were identified by Zhi-Qiang Zhang (Manaaki Whenua, Auckland, New Zealand), ants were identified by Darren Ward (Manaaki Whenua), scale insects by Milen Marinov (MPI, Auckland New Zealand) and the remainder of specimens were identified by SDJ Brown (Plant \& Food Research, Auckland, New Zealand).

\section{Temperature profiles of taro in hot water}

Taro corms of small $(\sim 700 \mathrm{~g})$ and large $(\sim 1250 \mathrm{~g})$ size were purchased from a local vegetable outlet in Auckland. Thermistor probes (Grant, Squirrel 1200 data logger, $45 \times 3 \mathrm{~mm}$ probes) 
were inserted in a shallow split on the surface of the taro to measure the surface temperature. Masking tape was used to secure the probe to the taro. To measure internal temperatures, Squirrel probes were inserted on an angle into the taro so that the tip of the probe was 5 -or $10-\mathrm{mm}$ deep into the flesh. This was done by drilling a $2-\mathrm{mm}$ hole into the taro slightly smaller in diameter of the $3-\mathrm{mm}$ probe and inserting the probe.

The HWT system consisted of fibreglass tubs (filled to a volume of $95 \mathrm{~L}$ ) as outlined in Woolf and Lay-Yee (1997). Temperature was measured at the "return" position in the bath.

Corms were slightly buoyant, and thus a metal mesh grid and part-filled bucket was required to hold the corms under water during treatment. Treatments were conducted at 48 for $30 \mathrm{~min}$ followed by $50^{\circ} \mathrm{C}$ for $30 \mathrm{~min}$.

\section{Most tolerant life stage of mites and nematodes to HWT}

Preparation of mites

Rhizoglyphus sp. mite eggs were collected from rotten parts of taro using a fine-tipped artists' paint brush and placed into 4 -mL specimen vials $\left(50 \mathrm{~mm} \times 12 \mathrm{~mm} ;\right.$ Samco $\left.^{\mathrm{Tm}}\right)$ containing $3 \mathrm{~mL}$ water. Once each vial contained $>100$ eggs, they were sealed with a push-in poly stopper cap, that had Parafilm ${ }^{\oplus}$ (Bemis, North America) wrapped around the thread and a second layer of Parafilm around the outside of the cap once it was pushed into the vial. Vials containing eggs were placed at ambient laboratory temperature $\left(22^{\circ} \mathrm{C}\right)$ until HWT 1-3 h later.

Nymph and adult Rhizoglyphus sp. were also collected from rotten parts of taro using a finetipped artists' paint brush and placed onto a fresh section of taro (approximately $3 \mathrm{~cm} \times 4 \mathrm{~cm}$ ) within separate plastic $120-\mathrm{mL}$ vials $(107 \mathrm{~mm} \times$ $42 \mathrm{~mm})$ with screw top lids and gauze $(0.085 \mathrm{~mm}$ aperture) at either end. Each vial contained c. 100 individuals of either nymphs or adults. The vial was then sealed with Parafilm in the same way as the vials containing eggs. Nymphs and adults were treated within $30 \mathrm{~h}$ of being set up in vials. Four replicates of mite eggs, nymphs and adults were set up for each treatment.

\section{Preparation of nematodes}

Root knot nematodes were sourced from infected tomato plants growing at the Nu'u Research station in Samoa. Infected roots were washed to remove soil, then chopped to approximately $20 \mathrm{~mm}$ in length with scissors. Distilled water was added to the roots which were then crushed using a plastic roller. The solution was thoroughly washed using tap water through $500-\mu \mathrm{m}$ and $20-\mu \mathrm{m}$ nested sieves. The $500-\mu \mathrm{m}$ sieve was used to remove the root material and the $20-\mu \mathrm{m}$ sieve was used to collect the eggs. The remaining solution was then poured through a $20-\mu \mathrm{m}$ sieve to collect the nematodes and eggs. The nematodes collected on the $20-\mu \mathrm{m}$ sieve were washed onto a tray covered and left at room temperature overnight.

The solution was poured into a beaker containing distilled water and used as a stock nematode (eggs and juvenile stage 2 [J2s]) suspension). Actively moving juveniles were picked from the suspension using pipettes $\left(\right.$ Brand $^{\oplus}$ Micro-Classic Controller and glass pipettes) under a microscope at $20-40 \times$ magnification and placed into $4-\mathrm{mL}$ specimen vials $(50 \mathrm{~mm}$ $\times 12 \mathrm{~mm}$; Samco) in groups of 20. Each sealed vial was filled with $2 \mathrm{~mL}$ of distilled water. The remaining solution, after the active J2s had been removed, was used as the egg solution; there were very low numbers of embryonated eggs (eggs in which the nematode juvenile can be seen). For the egg treatments, $2 \mathrm{~mL}$ of egg solution was added to each vial. This $2-\mathrm{mL}$ solution contained approximately 290 eggs of which approximately 20 were embryonated. Three and four replicates of the J2s and egg treatments, respectively, were set up for each treatment time. Vials were maintained at room temperature until HWT, which occurred on the same day.

\section{Hot water treatment}

Treatments were conducted in a custom-built water bath system, comprising four stainless steel water baths each $25 \mathrm{~L}$ in volume. A Grant temperature controller unit $\left( \pm 0.01^{\circ} \mathrm{C}, 1.5 \mathrm{~kW}\right.$ heater; model GRAVF, UK) with a stirrer blade was used to heat the water to $47^{\circ} \mathrm{C}$. Mites and 
nematodes were treated separately. When placing in the water baths, vials with mite nymphs and adults had to be tapped on the upper end with a finger to allow water to enter and remove air bubbles. Vials with mite or nematode eggs or nematode juveniles were placed on the bottom of the water bath. Each replicate was treated in a separate water bath.

Vials were treated at $47^{\circ} \mathrm{C}$ for $1,1.5,2,2.5,3$, 3.5 or $4 \mathrm{~min}$ and then removed and placed in a second water bath at $25^{\circ} \mathrm{C}$ to hydrocool for $10 \mathrm{~s}$ before being removed and placed on a towel to absorb water from vented vials. Controls for each of the eggs, nymphs, adult mites and for nematode eggs and juveniles were placed in the $25^{\circ} \mathrm{C}$ water bath for the duration of HWT treatment and hydrocooling.

After treatment, mite nymphs and adults along with juvenile nematodes in vials were placed at ambient laboratory temperate $\left(\sim 22^{\circ} \mathrm{C}\right)$ until assessments. Mite eggs were poured onto black filter paper in a Petri dish with a gauze covered hole in the base and paper towels underneath to absorb the water. Once the water was absorbed and the eggs became visible, the Petri dish was sealed with Parafilm and placed at ambient laboratory temperate until assessments. Nematode eggs were washed into Petri dishes and placed on trays in the dark at ambient laboratory temperate.

\section{Mite assessment}

Nymphs and adults were assessed one day after treatment when they were probed with a paint brush and assessed as live (movement) or dead (no movement). Assessments to determine hatched (viable) and unhatched (non-viable) mite eggs took place 5-8 days later when most eggs were expected to have hatched (Gerson et al. 1983).

\section{Nematode assessment}

Assessment of the J2s began $13 \mathrm{~h}$ post HWT. Individuals were classified as live (actively moving), moribund (body curved but not moving) or dead (body straight but not moving). Two assessments of eggs were carried out, the first 1-day and the second at 6-days post HWT. Mobile hatched juveniles were classified as live.

\section{Efficacy of HPW, HWT and combination treatment against pests on taro}

High pressure washer

A Honiball high pressure washing (HPW) system was installed at Atele Packhouse, Samoa in 2016. The system consists of a gantry of eight manifolds (at $140 \mathrm{~mm}$ spacing) each with eight vertically mounted fixed nozzles (at $100 \mathrm{~mm}$ spacing) over a bed of rotating brushes. The nozzles are Promax ${ }^{\oplus}$ QuickJet $^{\circledast}$ Spray Tips (QPTA-25-20: Spraying Systems, Auckland, New Zealand) situated at a height of $250 \mathrm{~mm}$ (measured vertically from the tip of the nozzle directly down to the top of the brushes). This results in a distance from the nozzles to the top of the taro of $\sim 180 \mathrm{~mm}$, depending on taro diameter (which will be influenced by taro size, cultivar and shape). The brush bed ( $630 \mathrm{~mm}$ wide $\times 1820 \mathrm{~mm}$ long) of flat brushes (not scalloped; from Talus Industries in Levin, New Zealand; Product Code FR BR SEG 654x140x25.0 (8KW) -013 BLK CRP PP) and the nozzles target taro corms as they sit between rollers; to reduce wear on brushes, the manifolds were aligned to the gaps between the brush rollers. The nozzles were mounted so that rows were angled $33^{\circ}$ laterally in alternating directions (left, right, left and so on) and blank nozzles were installed at the outer edge of each row (these nozzles were pointing into the wall of the washer and thus did not impact the taro). A final manifold of nozzles (QPTA-40-05) was included using clean water at ambient temperature to provide a final rinse of the taro. Taro were loaded on to the HPW brush bed 1-2 at a time and were under the nozzles for 12-15 sec.

\section{6 efficacy of HWT alone against mites and nematodes on taro}

In 2016, taro corms naturally infested with sufficient numbers of mites and nematodes were not able to be sourced, therefore taro (cv. 'Samoa 2 ') were artificially infested. For mite trials, small pieces of taro $(1 \mathrm{~cm} \times 1-2 \mathrm{~cm})$ infested with mite nymphs and adults were pinned to the outside of 
whole taro. Each piece of infested taro had $50+$ of each life stage present before being placed on the whole corm. Four pieces of infested taro were pinned to each taro corm. These corms were then placed in a bucket overnight and covered with a polythene bag to maintain humidity so that the taro and mites did not dry out. Five taro corms were set up for each treatment.

For nematodes, $150 \mu \mathrm{L}$ of egg solution was pipetted into 1.5-mL Eppendorf tubes. Each tube contained approximately 50 eggs, 7-8 of which were embryonated. The Eppendorf tubes containing the egg solution were pushed into taro corms, to a depth of approximately $5 \mathrm{~mm}$ and held in place with tape, with five tubes per corm and four corms in total. It was assumed that the tube conducts heat in a similar way to taro flesh.

Taro with mite nymphs/adults and nematode eggs were exposed to one of three treatments: $48^{\circ} \mathrm{C}$ for $40 \mathrm{~min} ; 49^{\circ} \mathrm{C}$ for $30 \mathrm{~min} ; 50^{\circ} \mathrm{C}$ for $15 \mathrm{~min}$. Five taro infested with mites, and a taro with nematode eggs in vials were kept at ambient laboratory conditions as an untreated control. Mite mortality was assessed 1 day after treatment. Nematode egg hatch was assessed six days after treatment.

\section{7 efficacy of HWT $+H P W$ against a range of pests on taro}

Low-quality taro, heavily infested with pests, were sourced from local growers. Eight-monthold taro of cultivars 'Samoa 2', 'Talo Fusi', and 'Talo Lani' were harvested on 26 May 2017 from a farm in Lotofaga, and brought to Nu'u Research Station (ca.1-h drive away) where they were coarsely washed by hand. The number of live/ viable pests on each of 192 taro was assessed over a 4 -day period using a $10 \times$ hand lens with LED lights. A unique number was assigned to each taro by drilling a numbered plastic tape label on to the taro. Once the pre-treatment assessment was complete, corms were stored in taro sacks at laboratory ambient conditions until treatment at Atele Packhouse on 31 May 2017.

Infested taro were treated in the 95-L hot water baths with one of the following treatments: HPW only, HWT at $46^{\circ} \mathrm{C}$ for $45 \mathrm{~min}$, HPW followed by $\mathrm{HWT}\left(\mathrm{HPW}+\mathrm{HWT}\right.$ ) at $46^{\circ} \mathrm{C}$ for $45 \mathrm{~min}$, $\mathrm{HWT}$ at $48^{\circ} \mathrm{C}$ for $30 \mathrm{~min}, \mathrm{HPW}+\mathrm{HWT}$ at $48^{\circ} \mathrm{C}$ for $30 \mathrm{~min}, \mathrm{HWT}$ at $50^{\circ} \mathrm{C}$ for $12.5 \mathrm{~min}, \mathrm{HPW}+$ $\mathrm{HWT}$ at $50^{\circ} \mathrm{C}$ for $12.5 \mathrm{~min}$. All taro receiving HPW were treated at 55 psi for $12-15 \mathrm{sec}$. Taro $(n=6-9)$ were selectively assigned to each treatment to get consistent numbers of mobile pests and eggs on each of three replicates for each treatment. An additional three replicates of eight infested taro were transported to Atele and back to Nu'u Research Station and remained untreated at ambient temperature for comparison with treatments. All taro associated with a single replicate of the three treatments, were completed before moving on to the next replicate. After treatment, taro were returned to Nu'u research centre and the numbers of mobile pests and eggs remaining on them were assessed within $24 \mathrm{~h}$ of treatment.

\section{Statistical analyses}

To assess the mortality response (shown in Figs. 1 \& 2), non-parametric LOESS fits (Cleveland et al. 1992) were calculated and plotted on an angular transformed scale (e.g. transform percentage $\mathrm{p}$ by $\arcsin [\operatorname{sqrt}(\mathrm{p} / 100)])$ in $\mathrm{R}$ (R Core Team 2015).

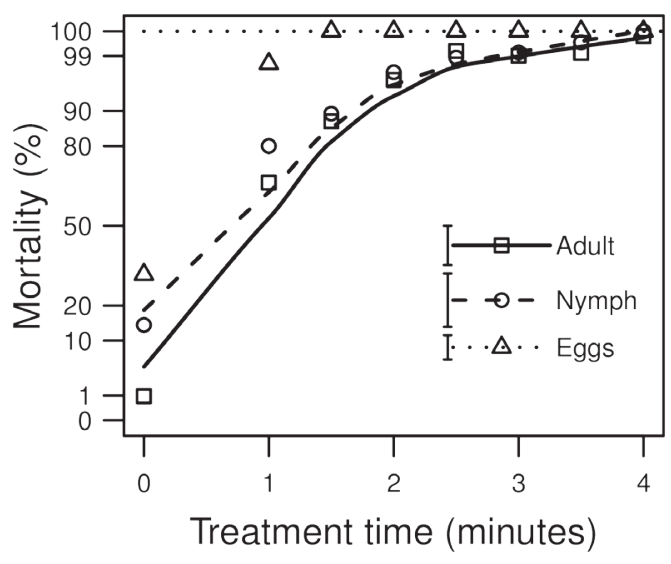

Figure 1 Percentage mortality of mite eggs $(\mathrm{n}=10863)$, nymphs $(\mathrm{n}=3450)$, and adults $(\mathrm{n}=2137)$ of Rhizoglyphus sp. after hot water treatment at $47^{\circ} \mathrm{C}$ for up to $4 \mathrm{~min}$. 
For each life stage, smoothed lines were drawn through the percentage mortality points after exposure to HWT, at each treatment time. The error bars in Figures 1 and 2 represent the rootmean-square of the errors of the fit for each line and are applicable over the entire mortality range on the arcsine scale.

Time mortality data for each replicate were fitted using the generalised linear model (Dobson \& Barnett 2008) capability of R with the complementary log-log (clog-log) link (Preisler \& Robertson 1989) and the HWT time as the explanatory variable. Specifically, the assumed form of response was $\log (-\log (1-p))=a+b T$, where $\mathrm{p}=$ expected mortality, and $\mathrm{T}=$ time of treatment. The coefficients, a (intercept) and b (slope), from the models were used to derive the estimated lethal time (LT) to achieve 99\% or $99.99 \%$ mortality $\left(\mathrm{LT}_{99}\right.$ or $\left.\mathrm{LT}_{99.99}\right)$, the time to achieve a mortality of $\mathrm{cm}+(1-\mathrm{cm}) \times 0.99$, where $\mathrm{cm}$ was the control mortality.

For each life stage, a geometric mean LT and its associated standard error (SEM) were estimated, from which a $95 \%$ confidence interval (CI) was calculated. Non-overlap of the $95 \%$ CIs is approximately equal to a test for difference at $\mathrm{P}=0.01$.

Data analysis for percent reduction in number of pests between pre-treatment assessment and post-treatment assessment (Fig. 3) was conducted in SAS version 9.4 (SAS Inc., USA). The percent reduction of mobile pests and eggs between pre- and post-treatment assessment was analysed based on a binomial model, adjusted for over dispersion and rare events (100\% or $0 \%$ reduction rate). Fitted percent reduction means and 95\% confidence intervals were compared and treatments were classified as significantly different where 95\% confidence intervals for pairwise comparisons did not overlap. Raw percentage reduction figures are presented in Figure 3.

\section{RESULTS}

\section{Pests collected from taro}

Mite species collected in 2016 are listed in Table 1. Rhizoglyphus minutus and R. setosus are mite

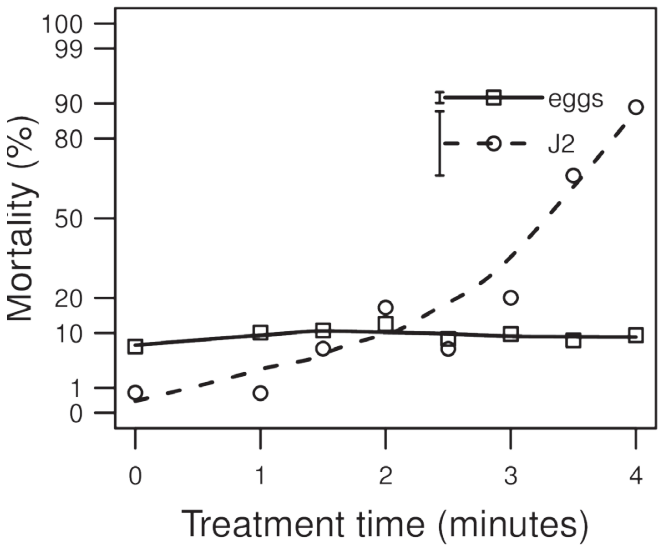

Figure 2 Percentage mortality of nematode eggs $(\mathrm{n}=9312)$ and juvenile stage $2(J 2, n=431)$ of Meloidogyne sp. after hot water treatment at $47^{\circ} \mathrm{C}$ for up to $4 \mathrm{~min}$.

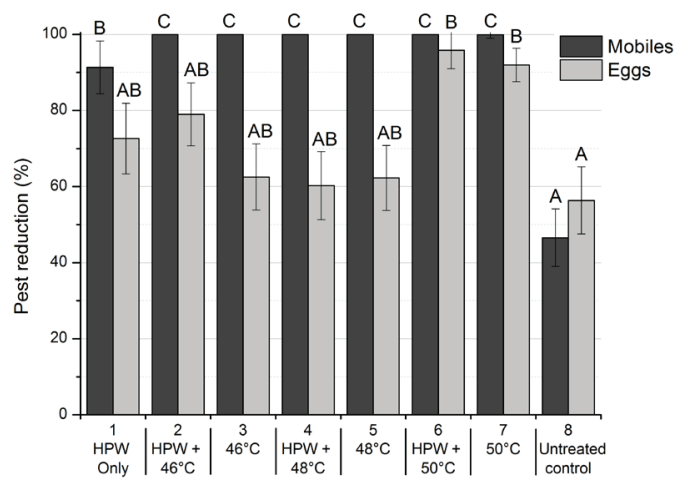

Figure 3 Percentage reduction in the number of pests between pre-treatment assessment and post-treatment assessment counts. HPW $=$ highpressure washing at $55 \mathrm{psi}$ for $12-15 \mathrm{sec} ; 46^{\circ} \mathrm{C}=$ hot water treatment (HWT) for $45 \mathrm{~min}, 48^{\circ} \mathrm{C}=$ $\mathrm{HWT}$ for $30 \mathrm{~min}$ and $50^{\circ} \mathrm{C}=\mathrm{HWT}$ for $12.5 \mathrm{~min}$. Common letters above bars indicate no statistical difference between treatments.

species commonly associated with taro. The other mites identified are soil predatory mites with no direct host relationship with taro. All mites were found on the surface or in soft depressions on taro. 
Table 1 Invertebrates collected and identified in 2016 and 2017 from taro grown in Samoa.

\begin{tabular}{ll}
\hline Year collected & Taxon Species (Class: Order: Family) \\
\hline 2016 & Ereynetidae sp. (Arachnida: Trombidiformes: Tydeoidea: Ereynetidae) \\
& Evimirus sp. (Arachnida: Acari: Mesostigmata: Eviphididae) \\
& Protogamasellopsis dioscorus (Arachnida: Acari: Mesostigmata: Rhodacaridae) \\
& Rhizoglyphus minutus (Arachnida: Acari: Astigmata: Acaridae) \\
& Rhizoglyphus setosus (Arachnida: Acari: Astigmata: Acaridae) \\
& Stratiolaelaps sp. (Arachnida: Acari: Mesostigmata: Laelapidae) \\
& Uroactinia sp. (Arachnida: Acari: Mesostigmata: Uropodidae: Uroactiniidae) \\
& Dactylosternum abdominale (Insecta: Coleoptera: Hydrophilidae) \\
& Dysmicoccus brevipes (Insecta: Hemiptera: Pseudococcidae) \\
& Mollusc cf Allopeas clavulinum (Mollusca: Gastropoda: Subulindae) \\
& Orphnaeus brevilabiatus (Myriapoda: Chilopoda: Geophilomorpha: Oryidae) \\
& Nylanderia vaga (Insecta: Hymenoptera: Formicidae) \\
& Pheidole fervens (Insecta: Hymenoptera: Formicidae) \\
& Prionopelta kraepelini (Insecta: Hymenoptera: Formicidae) \\
& Tapinoma melanocephalum (Insecta: Hymenoptera: Formicidae) \\
& Unidentified fly larvae (Insecta: Diptera) \\
& Unidentified leafhopper nymph (Insecta: Hemiptera: Cicadellidae) \\
& Unidentified millipede (Myriapoda: Diplopoda: Juliformia) \\
& Unidentified rove beetle (Insecta: Coleoptera: Staphylinidae: Paederinae) \\
& Unidentified weevil larva (Insecta: Coleoptera: Curculionidae)
\end{tabular}

A total of 36 specimens were collected in 2017 from low-quality taro. These were a small subset of the invertebrates found, and were species of interest that had not previously been identified (i.e. mites were not collected). Most of these species were found on the surface and in soft depressions on the taro. However, since the taro were of such low quality, some had large holes and crevices that would not usually be present on export-quality produce. Some of the invertebrates were found in these holes and crevices.

The specimens collected in 2017 were taken back to New Zealand and identified in the laboratory (Table 1).

\section{Temperature profiles of taro in hot water}

Times for the surface temperature of taro to reach lethal temperature of $47^{\circ} \mathrm{C}$ was $14-14.5 \mathrm{~min}$ after immersion in $\mathrm{HWT}$ at $48^{\circ} \mathrm{C}$ or $9.5 \mathrm{~min}$, after immersion in $\mathrm{HWT}$ at $50^{\circ} \mathrm{C}$, for small or large taro (Figs. $4 \& 5$ ). Corm flesh temperatures at 5 and $10 \mathrm{~mm}$ deep are also presented (Figs. $4 \& 5$ ).

\section{Most tolerant life stage of mites and nematodes to HWT}

Following $\mathrm{HWT}$ at $47^{\circ} \mathrm{C}, 100 \%$ mortality was reached after $1.5 \mathrm{~min}$ for mite eggs and $4 \mathrm{~min}$ for nymphs (Fig. 1). Mite nymphs and adults displayed 100 and $99.84 \%$ mortality after $4 \mathrm{~min}$ (Fig. 1). Mean LT estimates for 99\% mortality for mite nymphs and adults were $2.6 \mathrm{~min}$ and 2.9 min, respectively (Table 2). Control mortalities for mite eggs, nymphs and adults were 32, 16 and $1 \%$, respectively. LT estimates for $99.99 \%$ mortality were 3.9 and 4.1 for nymphs and adults, respectively (Table 2 ). The high LT estimate for 99.99\% mortality of nymphs in the first replicate was due to a flatter mortality response line (Table 2).

All treatments of nematode eggs (1-4 min at $47^{\circ} \mathrm{C}$ ) resulted in between 6.5 and $14.1 \%$ mortality and did not differ from the controls $(11.3 \pm 1.5$ $\%$ mortality). Mortality of J2 nematodes steadily increased over time, reaching approximately $90 \%$ mortality after 4 minutes of treatment in a 

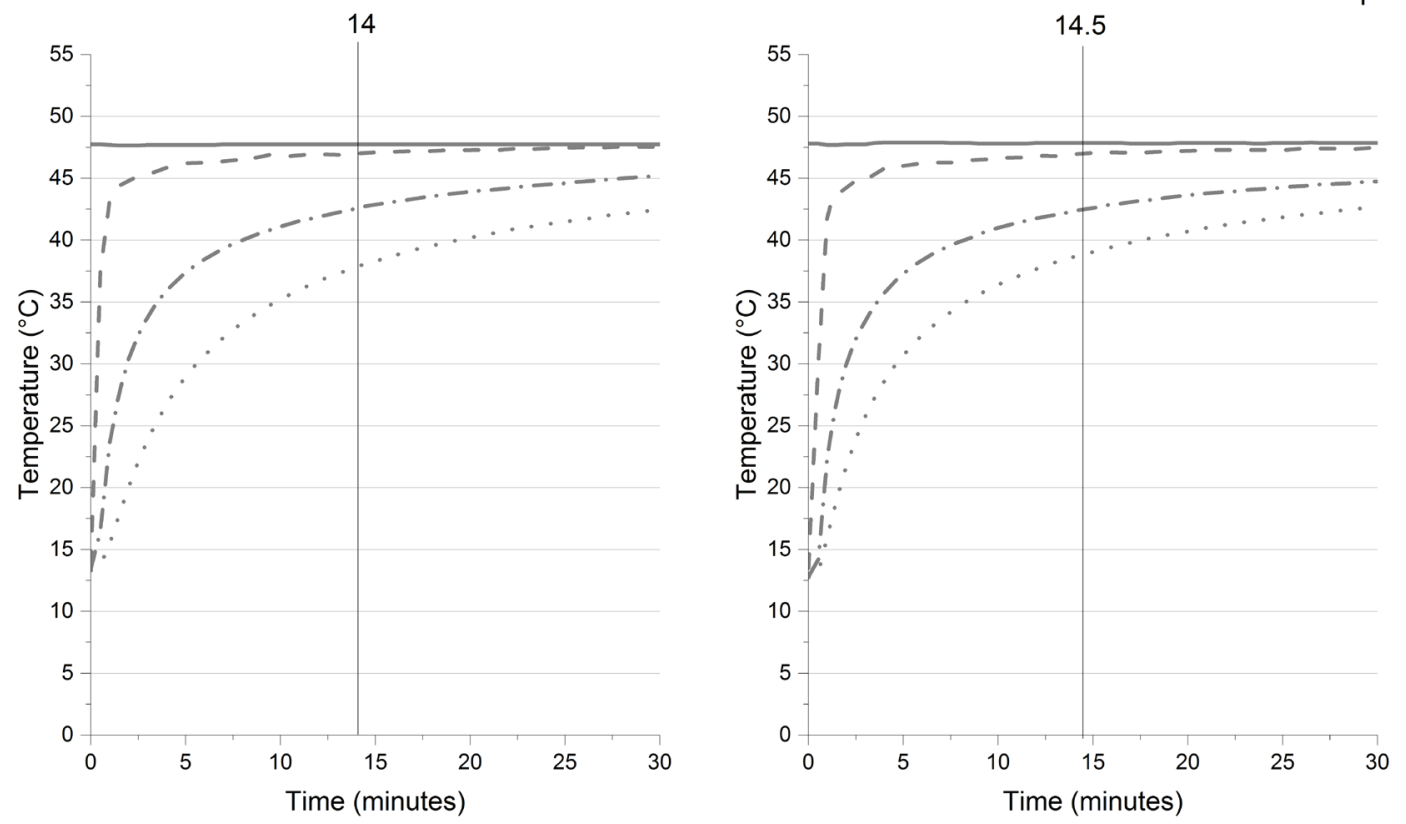

Figure 4 Temperature curves of small (left) and large (right) taro. A thermistor probe was attached to the surface and naked probes inserted $5 \mathrm{~mm}$ and $10 \mathrm{~mm}$ into the flesh. Taro were treated at $48^{\circ} \mathrm{C}$ for 30 minutes. The vertical lines indicate the time (minutes) at which the surface temperature reached $47^{\circ} \mathrm{C}$.

$47^{\circ} \mathrm{C}$ water bath (Fig. 2). Mean LT estimate for $99 \%$ mortality was $4.5 \mathrm{~min}$ (Table 3 ). J2 control mortality was $19.4 \pm 1.3 \%$.

\section{Efficacy of HPW, HWT and combination} treatment against mites and nematodes on taro 2016 efficacy of HWT alone against mites and nematodes on taro

In 2016, all treatments of mites on the surface of taro corms $\left(48^{\circ} \mathrm{C}\right.$ for $40 \mathrm{~min}, 49^{\circ} \mathrm{C}$ for $30 \mathrm{~min}$, $50^{\circ} \mathrm{C}$ for $15 \mathrm{~min}$ ) resulted in $100 \%$ mortality of nymphs, and adults. Average mortality within the controls was $18.4,0.6$, and $0.9 \%$ for eggs, nymphs, and adults, respectively. However, the same HWTs of nematode eggs, in tubes inserted in to and taped to the surface of taro, resulted in $10 \%$ mortality or less and did not differ from the control.
2017 efficacy of $H P W+H W T$ against a range of pests on taro

The number of pests on the low-quality taro used for the HPW + HWT trials was extremely high before treatment, ranging from a total of 664-2803 mobile pests and 14,631-26,227 eggs per treatment or 30-117 mobile pests and 5981034 eggs per taro corm. (Table 4). Most of the mobile pests were taro mites (Rhizoglyphus spp., 41.3\%) or potworms (Enchytraeidae, 49.4\%), and approximately 5.5\% were other mites, $1.9 \%$ were ants and $<1 \%$ were millipedes, beetles, flies, psocids, mealybugs, worms, termites, snails, spiders, earwigs, slugs, scale and unknown. Most of the eggs were taro mites (99.98\%) and $<0.01 \%$ were fly and ant eggs.

All combined treatments using HPW + HWT reduced the number of mobile pests by $100 \%$, as 

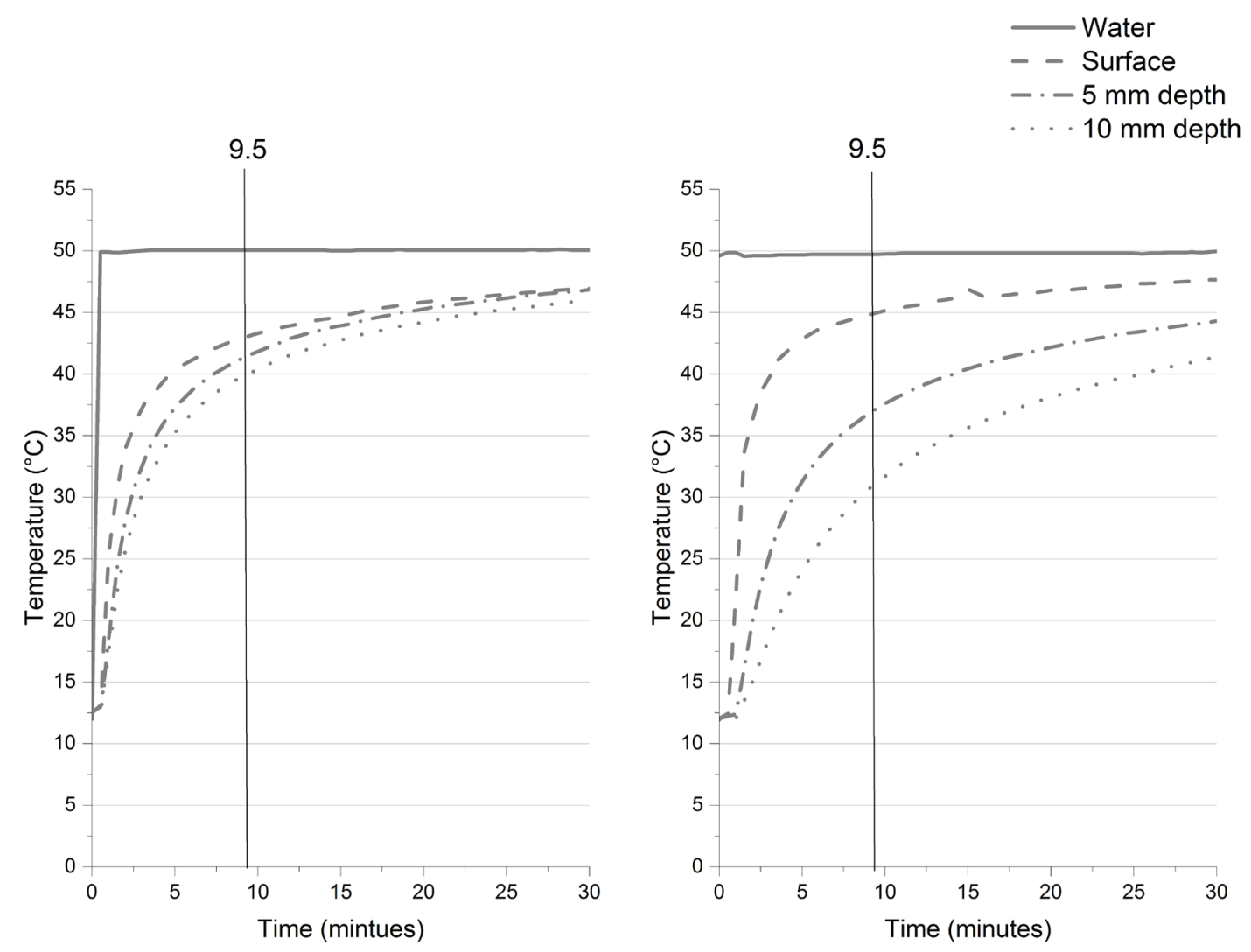

Figure 5 Temperature curves of small (left) and large (right) taro. A thermistor probe was attached to the surface and naked probes inserted $5 \mathrm{~mm}$ and $10 \mathrm{~mm}$ into the flesh. Taro were treated at $50^{\circ} \mathrm{C}$ for 30 minutes. The vertical lines indicate the time (minutes) at which the surface temperature reached $47^{\circ} \mathrm{C}$.

Table 2 Lethal time (LT) estimates (min) for $99 \%$ and $99.99 \%$ mortality of nymph and adult Rhizoglyphus sp. after hot water treatment at $47^{\circ} \mathrm{C}$.

\begin{tabular}{lcccccc}
\hline $\begin{array}{l}\text { Lethal estimate } \\
\text { Life stage }\end{array}$ & Mean & $95 \%$ CI & Rep 1 & Rep 2 & Rep 3 & Rep 4 \\
\hline LT $_{99}$ & & & & & & \\
Nymph & 2.6 & $2.0-3.4$ & 3.7 & 2.2 & 1.9 & 2.9 \\
Adult & 2.9 & $2.2-3.8$ & 2.6 & 3.2 & 3.1 & 2.9 \\
\hline LT $_{99.99}$ & & & & & & \\
Nymph & 3.9 & $2.7-5.6$ & 7.0 & 3.5 & 2.6 & 3.4 \\
Adult & 4.1 & $2.8-5.9$ & 3.9 & 4.3 & 3.8 & 4.5 \\
\hline
\end{tabular}


Table 3 Lethal time estimates ( $\mathrm{min}$ ) for 99\% mortality of juvenile stage 2 (J2s) Meloidogyne sp. after hot water treatment at $47^{\circ} \mathrm{C}$.

\begin{tabular}{lccccc}
\hline Life stage & Mean & $95 \%$ CI & Rep 1 & Rep 2 & Rep 3 \\
\hline J2 & 4.5 & $4.1-5.1$ & 4.4 & 4.8 & 4.4 \\
\hline
\end{tabular}

Table 4 Estimated total number of mobile and egg pests before treatment and after treatment. HPW = high-pressure washing at 55 psi for $12-15 \mathrm{sec}$; HWT = hot water treatment.

\begin{tabular}{|c|c|c|c|c|c|c|c|}
\hline \multirow[t]{2}{*}{ Trt no. } & \multirow[t]{2}{*}{ Trt description } & \multirow[b]{2}{*}{ Rep } & \multirow[b]{2}{*}{$\mathrm{N}$ taro } & \multicolumn{2}{|c|}{ Pre-treatment } & \multicolumn{2}{|c|}{ Post-treatment } \\
\hline & & & & $\mathrm{N}$ mobiles & $\mathrm{N}$ eggs & N mobiles & $\mathrm{N}$ eggs \\
\hline \multirow[t]{3}{*}{1} & \multirow[t]{3}{*}{ HPW only } & 1 & 7 & 329 & 5700 & 6 & 1850 \\
\hline & & 2 & 8 & 283 & 7500 & 17 & 580 \\
\hline & & 3 & 8 & 471 & 7000 & 71 & 3100 \\
\hline \multirow[t]{3}{*}{2} & \multirow{3}{*}{$\begin{array}{l}\mathrm{HPW}+\mathrm{HWT} \\
\left(46^{\circ} \mathrm{C}, 45 \mathrm{~min}\right)\end{array}$} & 1 & 8 & 777 & 7215 & 0 & 3105 \\
\hline & & 2 & 8 & 217 & 8462 & 0 & 400 \\
\hline & & 3 & 9 & 342 & 10550 & 0 & 2000 \\
\hline \multirow[t]{3}{*}{3} & \multirow{3}{*}{$\begin{array}{l}\text { HWT } \\
\left(46^{\circ} \mathrm{C}, 45 \mathrm{~min}\right)\end{array}$} & 1 & 7 & 295 & 3300 & 0 & 1650 \\
\hline & & 2 & 8 & 279 & 5072 & 0 & 1500 \\
\hline & & 3 & 8 & 315 & 5664 & 0 & 2110 \\
\hline \multirow[t]{3}{*}{4} & \multirow{3}{*}{$\begin{array}{l}\mathrm{HPW}+\mathrm{HWT} \\
\left(48^{\circ} \mathrm{C}, 30 \mathrm{~min}\right)\end{array}$} & 1 & 8 & 254 & 10700 & 0 & 3600 \\
\hline & & 2 & 8 & 301 & 5800 & 0 & 2150 \\
\hline & & 3 & 6 & 109 & 4500 & 0 & 2600 \\
\hline \multirow[t]{3}{*}{5} & \multirow{3}{*}{$\begin{array}{l}\mathrm{HWT} \\
\left(48^{\circ} \mathrm{C}, 30 \mathrm{~min}\right)\end{array}$} & 1 & 8 & 417 & 3791 & 0 & 2050 \\
\hline & & 2 & 8 & 470 & 7550 & 0 & 1760 \\
\hline & & 3 & 8 & 222 & 6718 & 0 & 3000 \\
\hline \multirow[t]{3}{*}{6} & \multirow{3}{*}{$\begin{array}{l}\mathrm{HPW}+\mathrm{HWT} \\
\left(50^{\circ} \mathrm{C}, 12.5\right. \\
\min )\end{array}$} & 1 & 8 & 279 & 4724 & 0 & 70 \\
\hline & & 2 & 8 & 399 & 5154 & 0 & 530 \\
\hline & & 3 & 8 & 295 & 4483 & 0 & 0 \\
\hline \multirow[t]{3}{*}{$\overline{7}$} & \multirow{3}{*}{$\begin{array}{l}\mathrm{HWT}\left(50^{\circ} \mathrm{C},\right. \\
12.5 \mathrm{~min})\end{array}$} & 1 & 8 & 367 & 5790 & 0 & 200 \\
\hline & & 2 & 8 & 380 & 6925 & 1 & 1200 \\
\hline & & 3 & 8 & 2056 & 4700 & 2 & 0 \\
\hline \multirow[t]{3}{*}{8} & \multirow[t]{3}{*}{ Untreated } & 1 & 8 & 796 & 7600 & 400 & 2875 \\
\hline & & 2 & 8 & 914 & 11200 & 708 & 6700 \\
\hline & & 3 & 8 & 699 & 6013 & 179 & 1253 \\
\hline
\end{tabular}

did HWTs at 46 and $48^{\circ} \mathrm{C}$ for 45 and 30 mins, respectively (Fig. 3). A $12.5-\mathrm{min} 50^{\circ} \mathrm{C} \mathrm{HWT}$ reduced the number of viable mobile pests by 99.9\% (Fig. 3). HPW alone achieved $73 \%$ and $91 \%$ reductions in eggs and live mobile pests, respectively (Fig. 3). Controls had 56 and 47\% reduction indicating that pests were moving off the taro between pre-treatment assessment and post-treatment assessment.

HPW or HWT or HPW + HWTs reduced 
the number of viable eggs found on taro by $62 \%$ to $96 \%$ with the $50^{\circ} \mathrm{C}$ treatments being most effective (Fig. 3).

\section{DISCUSSION}

A range of pests, predominantly taro mites, (Rhizoglyphus sp.), and pot-worms (Enchytraeidae), were found on taro. Pests were generally found on the surface of the taro and often in rotten soft depressions on the taro. Lowquality taro used for these trials often had holes and crevices where pests were found; however, these are not expected to be present on export quality taro entering New Zealand. Rotten soft patches can occasionally be found on exported taro, however observations indicate that HPW removes these soft patches. In this study HPW reduced the number of mobile and egg pests on heavily infested taro by around $90 \%$ and $70 \%$, respectively. Therefore, the addition of a HWT that achieves lethal surface temperatures is required to control the remaining surface pests on taro.

Mite adults and nymphs were more tolerant to HWT than eggs. Gotoh et al. (2013) also found that eggs of two-spotted spider mite, Tetranychus urticae, on strawberry leaf discs were more susceptible to hot-water treatment than adults.

Nematode eggs were more tolerant to HWT than nematode juveniles. There is little information on the relative tolerance of nematode eggs and juveniles; however, Cho et al. (2017) found that two plant parasitic nematodes Meloidogyne spp. and Pratylenchus spp. were completely killed at $48^{\circ} \mathrm{C}$ and $49^{\circ} \mathrm{C}$ for $30 \mathrm{sec}$ by HWT. In the current study, nematode eggs were very tolerant to HWT; therefore, controlling nematode eggs without damaging taro would be unlikely.

On taro, HWT times of 12.5-14 minutes at $50^{\circ} \mathrm{C}$ and $17.4-19.0$ minutes at $48^{\circ} \mathrm{C}$ are estimated to control mites and juvenile nematodes. These times are based on the lethal times for mite adults and juvenile nematodes (4.1 and 4.5 minutes, respectively) and the time it took for the surface temperature of taro to reach $47^{\circ} \mathrm{C}(9.5$ minutes in a $50^{\circ} \mathrm{C} \mathrm{HWT}$ and 14.5 minutes in a $48^{\circ} \mathrm{C}$ HWT).
An issue with previous studies attempting to demonstrate the efficacy of HWT on pests of taro, was that there have not been adequate pest densities to demonstrate efficacy (e.g. Buli et al. 2015). In the current trial, the combination of treatments of HPW and HWT at $50^{\circ} \mathrm{C}$ for 12.5 minutes, $48^{\circ} \mathrm{C}$ for 30 minutes or $46^{\circ} \mathrm{C}$ for 45 minutes reduced the numbers of viable mobile pests by $100 \%$, from 14,631-26,227 before treatment to zero after treatment, compared with a reduction of 2409 to 1287 for the untreated controls. In addition, a $50^{\circ} \mathrm{C}$ HWT for 12.5 minutes reduced the number of viable eggs by $92 \%$ without HPW and by $96 \%$ with HPW. However, the viability of eggs was difficult to assess within $24 \mathrm{~h}$ of treatment. Many of the eggs were a slightly darker colour than before treatment; therefore, further egg-viability studies are required. Additionally, remaining eggs were located in deep crevices and holes that would not usually be found on export taro.

In related taro-quality trials (Woolf et al. unpublished data), corm quality after HWT at $48^{\circ} \mathrm{C}$ for 30 mins or $50^{\circ} \mathrm{C}$ for $10-15$ mins was similar to that of untreated corms. However, longer durations and higher temperature $(>52.5-$ $55^{\circ} \mathrm{C}$ ) caused damage. Additionally, HPW at $55 \mathrm{psi}$ for $12-15 \mathrm{sec}$ did not detrimentally affect taro corms.

Based on the results of this study and previous studies, we recommend a HPW treatment of $55 \mathrm{psi}$ for $12-15$ secs followed by a $50^{\circ} \mathrm{C}$ HWT for $12.5 \mathrm{~min}, 48^{\circ} \mathrm{C}$ for $30 \mathrm{~min}$ or $46^{\circ} \mathrm{C}$ for $45 \mathrm{~min}$ to reduce mobile pest infestations on taro and decrease the need for subsequent $\mathrm{MB}$ fumigation on arrival to New Zealand.

\section{ACKNOWLEDGEMENTS}

This project was funded by the Ministry of Business, Innovation and Employment through the Better Border Biosecurity programme (B3; www.b3nz.org). We thank: Pueata Tanielu, Parate Matalavea, Setu Tomi and Asuelu Fa'alogo and other Samoa Ministry of Agriculture and Fisheries staff at the Nu'u Research Station, and Rashmi Kant and students from South Pacific University for their assistance; Atele Packhouse 
and staff for providing workspace and operational assistance; and Lily Armstrong (Quarantine Scientific) and Christina Fullerton (Plant \& Food Research) for technical assistance.

\section{REFERENCES}

Buli A, Lomavatu M, Ciri M 2015. Developing cleaner export pathways for taro in Fiji and Samoa. Acta Horticulturae 1105: 301-306.

Cho D, Park K, Kim Y, Koh K, Park Y 2017. Study on hot water immersion treatment for control of Meloidogyne spp. and Pratylenchus spp. in a ginger, Zingiber officinale. Korean Journal of Applied Entomology 56(2): 171-177.

Cleveland WS, Grosse E, Shyu WM 1992. Local regression models. In: Chambers JM, Hastie TJ eds. Statistical Models in S. Wadsworth \& Brooks/Cole, CA. Pp. 309-376.

Dobson AJ, Barnett AG 2008. Texts in Statistical Science: An Introduction to Generalized Linear Models. 3 ed. Florida, USA, CRC Press, Taylor \& Francis Group.

Gear I 2011. New Zealand Research Programme - Stakeholders in Methyl Bromide Reduction Update, Research programme 2011 - 2016, Annual International Conference on Methyl Bromide Alternatives and Emissions Reductions, San Diego, California, USA.

Gerson U, Capua S, Thorens D 1983. Life history and life tables of Rhizoglyphus robini Claparede (Acari: Astigmata: Acaridae). Acarologia 24(4): 439-448.

Gotoh T, Kitashima Y, Sato T 2013. Effect of hotwater treatment on the two-spotted spider mite, Tetranychus urticae, and its predator, Neoseiulus californicus (Acari: Tetranychidae, Phytoseiidae). International Journal of Acarology 39(7): 533-537.

Griffin M, Olsson SR, Jamieson LE, Kagy V, Mille C, Connolly PG, Woolf AB 2014. Reducing the risk of importing pest-infested citrus by applying high pressure washing treatments offshore. New Zealand Plant Protection 66: 109-115.

Jamieson LE, Chhagan A, Redpath SP, Griffin M J, Rohan C, Tunupopo F, Tugaga A, Connolly PG, Woolf AB 2016. Development of a hot water disinfestation treatment for taro exported from the Pacific Islands. New Zealand Plant Protection 69: 200-206.

MPI 2018. Approved Biosecurity Treatments. Ministry for Primary Industries, Wellington. https://www.mpi.govt.nz/dmsdocument/ 1555-approved-biosecurity-treatments-forrisk-goods (accessed 23 April 2018).

NZERMA 2011. Application for the reassessment of a hazardous substance under section 63 of the Hazardous Substances and New Organisms Act 1996. Name of substances: Methyl bromide and formulated substances containing methyl bromide, New Zealand Environmental Risk Management Authority. 107 p.

Page-Weir NEM, Jamieson LE, Bell NL, Rohan TC, Chhagan A, Clare G, Kean AM, Davis VA, Griffin M, Connolly PG 2013. Interceptions and hot water treatment of mites and nematodes on root crops from the Pacific Islands. New Zealand Plant Protection 66: $17-28$

Preisler HK, Robertson JL 1989. Analysis of timedose-mortality data. Journal of Economic Entomology 82: 1534-1542.

R Core Team 2015. R: A language and environment for statistical computing. Vienna, Austria, R Foundation for Statistical Computing.

UNEP 2014. Montreal protocol on substances that deplete the ozone layer United Nations Environment Programme. 2014 Report of the Methyl Bromide Technical Options Committee. 2014 Assessment Nairobi, Kenya. http://ozone.unep.org/Assessment_Panels/ TEAP/Reports/MBTOC/index.shtml

Woolf AB, Lay-Yee M 1997. Pretreatments at $38^{\circ} \mathrm{C}$ of 'Hass' avocado confer thermotolerance to $50^{\circ} \mathrm{C}$ hot-water treatments. HortScience 4(32): 705-708.

Woolf A, McDonald R, Rogers D, Olsson S, Redpath S, O'Donoghue E, Kagy V, Mille C, Cate L, Griffin M, Page-Weir N, Chhagan A, White A, Walker J, Jamieson L 2015. Advances in application of high pressure washing to enhance market access. Acta Horticulturae: 385-390. 